Клинико-иммунологические

корреляции у больных

хронической обструктивной

болезнью легких

и бронхиальной астмой

Шуганов Е.Г. • Распопина Н.А. • Салмаси Ж.М.

Шуганов Евгений Григорьевич -

д-р мед. наук, профессор,

профессор кафедры терапии

факультета усовершенствования

врачей

$\triangle 129110$, г. Москва, ул. Щепкина, 61/2-9, Российская Федерация.

Тел.: +7 (909) 9883455.

E-mail: shuganov.evgeny@yandex.ru

Распопина Наталья Автандиловна -

д-р мед. наук, профессор,

профессор кафедры внутренних,

профессиональных заболеваний

и пульмонологии ${ }^{2}$

Салмаси Жеан Мустафаевич -

д-р мед. наук, профессор,

профессор кафедры патофизиологии

и клинической патофизиологии ${ }^{3}$
Актуальность. Для повышения эффективности дифференциальной диагностики между хронической обструктивной болезнью легких (ХОБЛ) и бронхиальной астмой (БА) необходимо выявление новых биологических маркеров.

Цель - проведение дифференциальной диагностики между ХОБЛ и БА с помощью современных иммунологических методов обследования.

Материал и методы. Проведено сравнительное исследование поверхностных маркеров лимфоцитов периферической крови у 37 больных ХОБЛ и 49 больных БА в стадиях обострения и ремиссии. В качестве контроля изучали иммунологический статус 24 практически здоровых человек.

Результаты. Анализ содержания в периферической крови Т-лимфоцитов, В-лимфоцитов и NK-клеток при ХОБЛ и БА показал наличие изменений, характерных для любых воспалительных процессов. При этом получены существенные различия в изменениях поверхностного фенотипа лимфоцитов при ХОБЛ и БА. У больных ХОБЛ отмечено значимое увеличение содержания в крови цитотоксических Т-лимфоцитов $\left(\mathrm{CD}^{+}\right)$- до $34 \%$, а у больных БА, напротив, наблюдается снижение этого показателя до $21 \%$. Содержание в крови больных ХОБЛ $\mathrm{CD}^{+} 6^{+}$-лимфоцитов (NK-клетки) также достоверно повышено и составляет примерно 33\%, в то время как у больных БА практически не отличается от показателей здоровых людей - около $10 \%$.

Заключение. Выявленные различия отражают особенности патогенеза ХОБЛ и БА и могут использоваться в качестве дополнительного критерия дифференциальной диагностики.

Ключевые слова: хроническая обструктивная болезнь легких, бронхиальная астма, иммунное воспаление легочной ткани и бронхов, цитотоксические лимфоциты.

'ГБУз МО «Московский областной научно-исследовательский клинический институт им. М.Ф. Владимирского»; 129110, г. Москва, ул. Щепкина, 61/2, Российская Федерация

2 ГБОУ ВПО «Первый Московский государственный медицинский университет им. И.М. Сеченова» Минздрава России; 119991, г. Москва, ул. Трубецкая, 8/2, Российская Федерация

${ }^{3}$ ГБОУ ВПО «Российский национальный исследовательский медицинский университет им. Н.И. Пирогова»

Минздрава России; 117997, г. Москва, ул. Островитянова, 1, Российская Федерация 


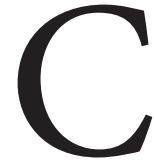
егодня бронхиальная астма (БА) и хроническая обструктивная болезнь легких (ХОБЛ) относятся к числу наиболее распространенных заболеваний, выступая одной из ведущих причин инвалидизации и смерти во всем мире [1]. Несмотря на значительные достижения в области диагностики и лечения этих заболеваний, в ряде случаев постановка дифференциального диагноза весьма затруднена. В этой связи представляется актуальным поиск новых маркеров ХОБЛ и БА, в частности, среди иммунологических показателей $[2,3]$.

Цель исследования - проведение дифференциальной диагностики с помощью современных иммунологических методов обследования у больных ХОБЛ и БА.

\section{Материал и методы}

В исследование включены 110 человек, из них больных ХОБЛ - 37 (средний возраст $58,1 \pm 1,6$ года), БА - 49 (средний возраст $38 \pm 2,0$ года), и 24 практически здоровых человека (средний возраст 52,6 22,8 года), составивших контрольную группу. В группе больных ХОБЛ 22 пациента находились в стадии обострения заболевания и 15 - ремиссии, в группе больных БА - 27 и 22 соответственно. У всех обследуемых измеряли функциональные параметры легких методом компьютерного спирометрического исследования с анализом кривой «поток объем» на спироанализаторе Custo Vit (Австрия). При оценке иммунологического статуса использовали метод непрямой иммунофлюоресценции для определения содержания в периферической крови лимфоцитов, экспрессирующих антигены CD3, CD4, CD8, CD16, CD20, CD23, CD25, CD54, CD71, CD72, HLA-DR, CD95 и мембранные иммуноглобулины M (mIgM) и $\mathrm{G}(\mathrm{mIgG})[4,5,6]$.

\section{Результаты и обсуждение}

Для определения иммунологического статуса оценивали представительство в периферической крови трех основных популяций лимфоцитов: Т-лимфоцитов, В-лимфоцитов и NK-клеток (табл. 1).

Обострение БА характеризовалось достоверным снижением общего количества Т-лимфоцитов $\left(\mathrm{CD}^{+}\right)$в периферической крови, что обусловлено уменьшением числа хелперно-индукторных лимфоцитов $\left(\mathrm{CD}^{+}\right)$и цитотоксических Т-лимфоцитов $\left(\mathrm{CD}^{+}\right)$. Отражением этих изменений стало статистически значимое повышение иммунорегуляторного индекса (CD4/CD8) с 1,42 $\pm 0,04$ у здоровых доноров до $1,65 \pm 0,005$ у больных БА $(\mathrm{p}<0,001)$. У больных ХОБЛ, напротив, наблюдалось существенное увеличение содержания в крови цитотоксических лимфоцитов независимо от стадии заболевания $(\mathrm{p}<0,001)$. При этом у больных ХОБЛ в стадии ремиссии наблюдалось снижение содержания в крови Т-лимфоцитов (до $52,28 \pm 2,27 \%$ ) по сравнению со здоровыми людьми. Одновременно в крови больных ХОБЛ в период ремиссии зарегистрировано высокое содержание Т-лимфоцитов с фенотипом $\mathrm{CD}^{+} \mathrm{CD}^{+} \mathrm{CD}^{+} \quad(18,44 \pm 4,02 \%)$, что, по-видимому, указывает на чрезмерную стимуляцию

Таблица 1. Популяционный и субпопуляционный состав лимфоцитов периферической крови больных атопической БА и ХОБЛ в зависимости от стадии заболевания, \%

\begin{tabular}{|c|c|c|c|c|c|c|}
\hline \multirow{2}{*}{$\begin{array}{l}\text { Популяции } \\
\text { лимфоцитов }\end{array}$} & \multirow{2}{*}{$\begin{array}{l}\text { Маркеры } \\
\text { лимфоцитов }\end{array}$} & \multirow{2}{*}{$\begin{array}{c}\text { Здоровые } \\
\text { доноры } \\
(n=24)\end{array}$} & \multicolumn{2}{|c|}{ Больные БА $(n=49)$} & \multicolumn{2}{|c|}{ Больные ХОБЛ $(n=37)$} \\
\hline & & & $\begin{array}{l}\text { в стадии } \\
\text { обострения } \\
(n=27)\end{array}$ & $\begin{array}{l}\text { в стадии } \\
\text { ремиссии } \\
(\mathrm{n}=22)\end{array}$ & $\begin{array}{l}\text { в стадии } \\
\text { обострения } \\
(n=22)\end{array}$ & $\begin{array}{c}\text { в стадии } \\
\text { ремиссии } \\
(n=15)\end{array}$ \\
\hline \multirow[t]{3}{*}{ Т-лимфоциты } & CD3 & $65,20 \pm 0,66$ & $56,64 \pm 1,72^{*}$ & $50,52 \pm 1,02^{*}$ & $61,65 \pm 2,95$ & $52,28 \pm 2,26^{* *}$ \\
\hline & CD4 & $36,48 \pm 0,95$ & $33,42 \pm 0,73^{* *}$ & $32,96 \pm 0,53^{* * *}$ & $32,60 \pm 0,71^{* * *}$ & $37,86 \pm 2,61$ \\
\hline & CD8 & $25,90 \pm 0,50$ & $20,69 \pm 0,73^{*}$ & $18,81 \pm 0,27^{*}$ & $36,23 \pm 2,54^{*}$ & $32,92 \pm 1,96^{* *}$ \\
\hline \multirow[t]{2}{*}{ NK-клетки } & CD16 & $13,22 \pm 0,43$ & $9,73 \pm 0,33^{*}$ & $12,41 \pm 0,74$ & $25,24 \pm 3,16^{*}$ & $22,11 \pm 1,07^{*}$ \\
\hline & CD56 & $4,47 \pm 0,09$ & $15,58 \pm 1,14^{*}$ & $9,57 \pm 0,55^{*}$ & $22,18 \pm 2,13^{*}$ & $17,94 \pm 1,99^{*}$ \\
\hline \multirow[t]{4}{*}{ В-лимфоциты } & CD20 & $10,15 \pm 0,16$ & $17,44 \pm 0,64^{*}$ & $12,40 \pm 0,52$ & $26,35 \pm 1,92^{*}$ & $11,56 \pm 0,61$ \\
\hline & CD72 & $10,10 \pm 0,39$ & $15,67 \pm 0,56^{*}$ & $10,18 \pm 0,35$ & $18,56 \pm 2,34^{* *}$ & $10,34 \pm 1,40$ \\
\hline & $\mathrm{mlgM}$ & $5,13 \pm 0,18$ & $14,22 \pm 0,32^{*}$ & $8,89 \pm 0,26^{* *}$ & $29,14 \pm 2,18^{*}$ & $13,13 \pm 0,99 * *$ \\
\hline & $\operatorname{mlg} G$ & $6,54 \pm 0,48$ & $14,17 \pm 0,31^{*}$ & $8,94 \pm 0,22^{* * *}$ & $21,65 \pm 1,15^{*}$ & $12,88 \pm 1,60^{* *}$ \\
\hline
\end{tabular}

БА - бронхиальная астма, ХОБЛ - хроническая обструктивная болезнь легких

Данные представлены как средние значения (М) и стандартная ошибка среднего ( $\pm \mathrm{m})$

${ }^{*} \mathrm{p}<0,001 ;{ }^{* *} \mathrm{p}<0,01 ;{ }^{* * *} \mathrm{p}<0,05$ (по сравнению со здоровыми донорами) 
Т-клеточного звена иммунной системы у этих пациентов.

При изучении содержания натуральных киллеров в крови больных атопической БА выявлено увеличение количества активированных NKклеток (CD56'-лимфоциты). У больных ХОБЛ наблюдалось выраженное повышение содержания в крови обеих субпопуляций лимфоцитов - CD56 и CD16 ( $<$ 0,0001). Резкое увеличение содержания NK-клеток при ХОБЛ, предположительно, связано с тем, что их пролиферацию усиливают интерлейкин 1 и фактор некроза опухоли- $\alpha$ - цитокины, синтез которых существенно повышен при ХОБЛ $[6,7]$.

Исследование содержания В-лимфоцитов в периферической крови больных в стадию обострения как при БА, так и при ХОБЛ демонстрирует увеличение всех дифференцированных форм В-лимфоцитов. Общее содержание В-лимфоцитов $\left(\mathrm{CD} 20^{+}\right)$увеличивается у больных атопической БА в стадии обострения более чем в 1,5 раза. Количество примированных антигеном В-лимфоцитов (CD72+) также повышено в 1,5 раза относительно показателя здоровых доноров. У больных ХОБЛ содержание этих форм лимфоцитов было еще выше. Что касается стадии ремиссии БА и ХОБЛ, уровень маркеров $\mathrm{CD} 20^{+}$и $\mathrm{CD}^{+} 2^{+} \mathrm{B}$-лимфоцитов практически не отличался от показателей здоровых людей. Анализ содержания в периферической крови зрелых В-клеток, несущих $\mathrm{mIgM}$ и $\mathrm{mIgG}$, показал их существенное увеличение независимо от стадии заболевания в обеих группах больных.

Из представленных результатов следует: при обострении БА и ХОБЛ наблюдается существенное повышение количества В-лимфоцитов всех стадий дифференцировки, что свидетельствует об активации В-клеточного звена иммунной системы в целом. Значимое повышение содержания в крови лимфоцитов, экспрессирующих поверхностные иммуноглобулины, позволяет, в свою очередь, утверждать, что у больных БА и ХОБЛ В-клеточная активация является отражением постоянно поддерживаемого процесса антигенной стимуляции с хроническим течением.

Анализ изменений основных популяций лимфоцитов у больных БА и ХОБЛ позволил выявить следующие особенности:

1) при БА как в стадии ремиссии, так и в период обострения наблюдается уменьшение общего количества Т-лимфоцитов $\left(\mathrm{CD}^{+}\right)$за счет субпопуляций Т-хелперов и цитотоксических Т-лимфоцитов, причем содержание последних снижается в большей степени. У больных ХОБЛ независимо от стадии заболевания, напротив, отмечено существенное увеличение содержания в крови цитотоксических Т-лимфоцитов;

2) при БА наблюдается повышение уровня только CD56+-лимфоцитов, в то время как содержание $\mathrm{CD} 16^{+}$-лимфоцитов находится в пределах нормы или даже снижено. У больных ХОБЛ происходит резкое повышение содержания в крови обеих субпопуляций NK-клеток независимо от стадии заболевания;

3) изменения В-клеточного звена иммунной системы у больных БА и ХОБЛ можно охарактеризовать как однонаправленные. При обоих заболеваниях в стадии ремиссии, в отличие от стадии обострения, не наблюдается достоверных изменений в содержании в периферической крови общего количества В-лимфоцитов $\left(\mathrm{CD} 20^{+}\right)$, а также лимфоцитов, экспрессирующих CD72-антигены. В то же время количество зрелых В-лимфоцитов, начавших синтез антител и экспрессирующих иммуноглобулины на клеточной мембране (mIgM+-лимфоциты), как и $\mathrm{mIgG}^{+}$-лимфоцитов, оказывается увеличенным у больных БА и ХОБЛ не только в период обострения, но и в стадии ремиссии.

Таким образом, при БА независимо от стадии заболевания понижается содержание Т-лимфоцитов $\left(\mathrm{CD}^{+}\right)$преимущественно за счет уменьшения количества цитотоксических клеток $\left(\mathrm{CD}^{+}\right)$. Напротив, для больных ХОБЛ независимо от стадии заболевания характерно резкое увеличение содержания в крови цитотоксических лимфоцитов, в том числе цитотоксических Т-лимфоцитов и NK-клеток. Возможно, именно резкое повышение цитотоксических лимфоцитов в организме больных ХОБЛ играет ведущую роль в повреждении легочной ткани и быстром развитии эмфиземы и пневмосклероза.

Анализ содержания в крови больных лимфоцитов, экспрессирующих активационные антигены (табл. 2), показал, что и у больных ХОБЛ, и у больных БА независимо от стадии заболевания повышено содержание $\mathrm{CD} 25^{+}$-

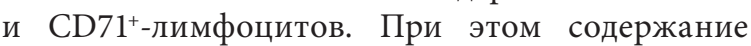
HLA-DR+-лимфоцитов в крови больных существенно увеличивалось только в стадию обострения. Характерно, что при обострении ХОБЛ содержание в крови активированных форм лимфоцитов было существенно выше, чем при обострении БА.

У больных БА независимо от стадии заболевания наблюдался достоверный прирост количества активированных В-лимфоцитов $\left(\mathrm{CD} 23^{+}\right)$по сравнению со здоровыми донорами. У больных 
Таблица 2. Характеристика активационных маркеров лимфоцитов периферической крови больных атопической БА и ХОБЛ в зависимости от стадии заболевания, \%

\begin{tabular}{|c|c|c|c|c|c|}
\hline \multirow{2}{*}{$\begin{array}{l}\text { Маркер } \\
\text { активации }\end{array}$} & \multirow{2}{*}{$\begin{array}{l}\text { Здоровые доноры } \\
(\mathrm{n}=24)\end{array}$} & \multicolumn{2}{|l|}{ Больные БА $(n=49)$} & \multicolumn{2}{|l|}{ Больные ХОБЛ $(n=37)$} \\
\hline & & $\begin{array}{l}\text { в стадии обострения } \\
\quad(\mathrm{n}=27)\end{array}$ & $\begin{array}{l}\text { в стадии ремиссии } \\
(\mathrm{n}=22)\end{array}$ & $\begin{array}{l}\text { в стадии обострения } \\
\quad(\mathrm{n}=22)\end{array}$ & $\begin{array}{l}\text { в стадии ремиссии } \\
(\mathrm{n}=15)\end{array}$ \\
\hline CD23 & $5,29 \pm 0,30$ & $\begin{array}{c}13,26 \pm 0,36 \\
p<0,001\end{array}$ & $\begin{array}{c}9,76 \pm 0,39 \\
p<0,05\end{array}$ & $\begin{array}{c}17,85 \pm 2,53 \\
p<0,001\end{array}$ & $6,38 \pm 0,63$ \\
\hline CD25 & $6,04 \pm 0,24$ & $\begin{array}{c}15,70 \pm 0,37 \\
p<0,001\end{array}$ & $\begin{array}{c}11,83 \pm 0,26 \\
p<0,01\end{array}$ & $\begin{array}{c}22,81 \pm 2,54 \\
p<0,001\end{array}$ & $\begin{array}{c}12,34 \pm 1,35 \\
p<0,01\end{array}$ \\
\hline CD71 & $6,32 \pm 0,21$ & $\begin{array}{c}13,11 \pm 0,77 \\
p<0,001\end{array}$ & $\begin{array}{c}11,3 \pm 0,34 \\
p<0,01\end{array}$ & $\begin{array}{c}22,91 \pm 2,26 \\
p<0,001\end{array}$ & $\begin{array}{c}12,38 \pm 2,19 \\
p<0,01\end{array}$ \\
\hline HLA-DR & $11,83 \pm 0,30$ & $\begin{array}{c}23,85 \pm 0,65 \\
p<0,001\end{array}$ & $12,92 \pm 0,29$ & $\begin{array}{c}29,18 \pm 0,72 \\
p<0,001\end{array}$ & $11,67 \pm 2,15$ \\
\hline CD54 & $5,55 \pm 0,33$ & $\begin{array}{c}27,92 \pm 1,55 \\
p<0,001\end{array}$ & $\begin{array}{c}26,29 \pm 0,69 \\
p<0,001\end{array}$ & $\begin{array}{c}15,91 \pm 2,79 \\
p<0,001\end{array}$ & $\begin{array}{c}15,56 \pm 2,31 \\
p<0,001\end{array}$ \\
\hline CD95 & $4,42 \pm 0,20$ & $3,74 \pm 0,68$ & $\begin{array}{c}7,74 \pm 0,32 \\
p<0,01\end{array}$ & $\begin{array}{c}15,04 \pm 1,06 \\
p<0,001\end{array}$ & $\begin{array}{c}13,64 \pm 1,84 \\
p<0,01\end{array}$ \\
\hline CD178 & $9,22 \pm 1,04$ & $\begin{array}{c}13,85 \pm 1,09 \\
p<0,01\end{array}$ & - & $\begin{array}{c}4,82 \pm 2,34 \\
p<0,05\end{array}$ & - \\
\hline CD25/CD95 & $1,43 \pm 0,06$ & $\begin{array}{c}3,17 \pm 0,45 \\
p<0,01\end{array}$ & $\begin{array}{c}1,20 \pm 0,08 \\
p<0,05\end{array}$ & $1,05 \pm 0,13$ & $1,00 \pm 0,19$ \\
\hline HLA-DR/CD95 & $3,04 \pm 0,33$ & $\begin{array}{c}5,23 \pm 0,64 \\
p<0,01\end{array}$ & $\begin{array}{c}1,75 \pm 0,01 \\
p<0,01\end{array}$ & $\begin{array}{c}1,95 \pm 0,14 \\
p<0,01\end{array}$ & $\begin{array}{c}1,14 \pm 0,49 \\
p<0,01\end{array}$ \\
\hline
\end{tabular}

БА - бронхиальная астма, ХОБЛ - хроническая обструктивная болезнь легких

Данные представлены как средние значения (М) и стандартная ошибка среднего $( \pm \mathrm{m})$

ХОБЛ существенное повышение содержания в крови $\mathrm{CD} 23^{+}$-лимфоцитов происходило в стадию обострения заболевания. Полученные результаты не позволяют считать повышение содержания в крови $\mathrm{CD} 23^{+}$-лимфоцитов патогномоничным только для атопических заболеваний, в частности БА.

И при ХОБЛ, и при БА независимо от стадии заболевания отмечено существенное увеличение в крови содержания лимфоцитов, экспрессирующих рецептор адгезии CD54 (ICAM-1), что, по-видимому, отражает повышенную готовность лимфоцитов крови к миграции в ткань и их взаимодействие с антигенпрезентирующими клетками. В среднем уровень $\mathrm{CD} 54^{+}$-лимфоцитов в крови больных атопической БА был почти вдвое выше, чем у больных ХОБЛ.

Интересные результаты получены при оценке содержания в крови лимфоцитов, экспрессирующих рецепторы индукции Fas-зависимого апоптоза CD95 и лиганда к этому рецептору CD178. У больных БА в стадии обострения по сравнению со здоровыми донорами содержание в крови лимфоцитов, экспрессирующих Fas-антиген, имело тенденцию к понижению, при этом содержание в крови $\mathrm{CD}^{+} 5^{+}$-лимфоцитов существенно возрастало. У больных ХОБЛ независимо от стадии заболевания содержание в крови лимфоцитов, экспрессирующих Fas-антиген, резко увеличивалось. Содержание в периферической крови лимфоцитов, экспрессирующих Fas-лиганд CD178, исследовали только в группах больных с обострением заболевания. Оказалось, что у больных БА содержание в крови $\mathrm{CD}_{178^{+}-}$ лимфоцитов было существенно выше, чем у здоровых людей, в то время как у больных ХОБЛ этот показатель был вдвое ниже, чем у здоровых доноров.

Для оценки изменений в иммунной системе приоритетное значение имеет не абсолютное количество лимфоцитов, экспрессирующих конкретные маркеры, а изменение функциональной активности лимфоцитов, сопряженное с соотношением маркеров CD25/CD95 и HLADR/CD95 в популяции [8]. Результаты нашего исследования показали, что при обострении БА соотношение CD25/CD95 увеличено в 2,5 раза по сравнению с соответствующими параметрами 
здоровых доноров. Это отражает более высокую готовность клеток вступить на путь пролиферации и дифференцировки, а не активационного апоптоза. Соотношение HLA-DR/CD95 в период обострения БА по сравнению со здоровыми донорами также было увеличено, что указывает на превышение готовности клеток к приобретению позднего дифференцировочного антигена HLADR над готовностью клеток вступать на путь активационного апоптоза. Из сопоставления степени повышения CD25/CD95 по сравнению c HLA-DR/CD95 следует, что в ходе обострения БА процессы пролиферации и дифференцировки лимфоцитов преобладают над процессами активационного апоптоза.

Иной характер активационных соотношений CD25/CD95 и HLA-DR/CD95 наблюдался при ремиссии БА. Соотношение CD25/CD95 уменьшалось, что, с одной стороны, свидетельствует о снижении остроты процесса, а с другой - отражает преобладание повышенной готовности лимфоцитов к индукции Fas-опосредованного апоптоза (CD95) над их готовностью к пролиферации (CD25). Нарушение баланса CD95+-лимфоцитов и $\mathrm{HLA}-\mathrm{DR}^{+}$-лимфоцитов при ремиссии БА проявлялось в виде достоверного снижения показателя HLA-DR/CD95 до 1,75 $\pm 0,01$ у больных БА по сравнению с 3,04 \pm 0,33 у здоровых доноров. Если говорить о направлении перестройки иммунной системы, в данном случае мы наблюдаем преобладание процессов активационного апоптоза лимфоцитов (CD95) над их готовностью к дифференцировке и приобретению позднего дифференцировочного антигена (HLA-DR). Повидимому, для периода ремиссии БА характерно формирование иммунологической анергии.

У больных ХОБЛ независимо от стадии заболевания не отмечено изменения соотношения CD25/CD95, а соотношение HLA-DR/CD95 было ниже, чем у здоровых людей. Это может быть связано с высоким содержанием в крови больных ХОБЛ CD95+-лимфоцитов, характерным для активации иммунной системы [6].

При оценке полученных результатов необходимо учитывать, что развитие Fasиндуцированного апоптоза происходит только после взаимодействия Fas-антигена c Fasлигандом [7, 8]. В этой связи несмотря на более высокое содержание $\mathrm{CD}^{+} 5^{+}$-лимфоцитов в крови больных ХОБЛ по сравнению с обследованными больными БА можно предположить, что из-за низкого содержания лимфоцитов, экспрессирующих Fas-антиген, для ХОБЛ характерен более низкий уровень апоптоза лимфоцитов, чем для БА.

Сравнительный анализ результатов изучения активационных маркеров лимфоцитов при БА и ХОБЛ позволил выявить следующие особенности:

1) обострение при обоих заболеваниях приводит к существенному повышению содержания в крови лимфоцитов, экспрессирующих активационные антигены CD23, CD25, CD71 и HLA-DR;

2) в стадию ремиссии у больных атопической БА и ХОБЛ сохраняется повышенное содержание лимфоцитов, несущих на поверхности ранние активационные антигены CD25 и CD71. Эти изменения можно объяснить тем, что клиническая ремиссия при обоих заболеваниях не сопровождается полной иммунологической ремиссией, то есть иммунопатологические процессы не «выключаются»;

3) содержание в крови больных БА CD23+лимфоцитов, экспрессирующих низкоаффинный рецептор к иммуноглобулину Е, оставалось повышенным не только в стадию обострения, но и ремиссии, тогда как у больных ХОБЛ в период ремиссии и у здоровых доноров этот показатель практически не различался;

4) содержание в крови больных БА и ХОБЛ CD54+-лимфоцитов повышалось независимо от стадии заболевания, однако у больных БА этот показатель был почти вдвое выше, чем при ХОБЛ. Более высокое содержание в крови больных БА лимфоцитов, экспрессирующих молекулу адгезии ICAM-1, может быть связано с особенностями цитокинового профиля у больных БА $[9,10]$.

Таким образом, изменения в иммунной системе, развивающиеся при ХОБЛ и при БА, имеют ряд существенных различий в первую очередь за счет существенного повышения содержания цитотоксических лимфоцитов в крови больных ХОБЛ. Можно предположить, что именно высокий цитотоксический потенциал иммунной системы больных ХОБЛ служит причиной повреждения легочной ткани, вызывая развитие пневмосклероза и эмфиземы легких. Высокая активность цитотоксических лимфоцитов и NKклеток, по всей видимости, является одним из факторов наследственной предрасположенности к развитию ХОБЛ. В свою очередь, высокая «выживаемость» цитотоксических лимфоцитов у больных ХОБЛ может быть объяснена снижением их апоптоза из-за низкой экспрессии Fasлиганда. (宅) 


\section{Литература (References)}

1. Global Initiative for Chronic Obstruction Lung Disease. Global Strategy for the Diagnosis, Management, and Prevention of Chronic Obstructive Pulmonary Disease (Updated 2007). Available from: www.goldcopd.com

2. Порядин ГВ, Салмаси ЖМ, Зильбер ИЕ. Особенности поверхностного фенотипа лимфоцитов при ХОБЛ. В: Материалы Х Международного конгресса «Современные проблемы аллергологии, иммунологии и иммунофармакологии». Казань, 20-23 мая 2009 г. с. 304.

(Poryadin GV, Salmasi ZhM, Zil'ber IE. Characteristic of surface lymphocytes phenotype in COPD. In: Proceedings of the $X$ International Congress "Contemporary issues of allergology, immunology and immunopharmacology"; 2009 May 20-23; Kazan, Russia. p. 304. Russian).

3.Порядин ГВ, Салмаси ЖМ, Макарков АИ. Механизмы регуляции экспрессии поверх- ностных структур дифференцированного лимфоцита. Иммунология. 1997;(3):4-8. (Poryadin GV, Salmasi ZhM, Makarkov Al. [Surface structures expression regulatory mechanisms in differentiated lymphocyte]. Immunologiya. 1997;(3):4-8. Russian).

4. Казимирский АН, Салмаси ЖМ, Журавлева НЕ, Семенова ЛЮ, Порядин ГВ, Алиева 30. Особенности иммунного ответа в процессе развития воспаления при атопии. Клиническая патофизиология. 2002;(1):5-11.

(Kazimirskiy AN, Salmasi ZhM, Zhuravleva NE, Semenova LYu, Poryadin GV, Alieva ZO. [Characteristics of immune response in atopic inflammation]. Klinicheskaya patofiziologiya. 2002;(1):5-11. Russian).

5. Фримель Г, ред. Иммунологические методы. [Перевод с нем.]. М.: Медицина; 1987. 472 с.

(Friemel $\mathrm{H}$, editor. Immunological working methods. Moscow: Meditsina; 1987. 472 p. Russian).
6. Harnett M, Rigley K. The role of G-proteins versus protein tyrosine kinases in the regulation of lymphocyte activation. Immunol Today. 1992;13(12):482-6.

7. Stalder T, Hahn S, Erb P. Fas antigen is the major target molecule for $\mathrm{CD}^{+} \mathrm{T}$ cell-mediated cytotoxicity. J Immunol. 1994;152(3):1127-33.

8. Robertson MJ, Cameron C, Lazo S, Cochran KJ, Voss SD, Ritz J. Costimulation of human natural killer cell proliferation: role of accessory cytokines and cell contact-dependent signals. Nat Immun. 1996-1997;15(5):213-26.

9. Schwarting R, Castello R, Moldenhauer G, Pezzutto A, von Hoegen I, Ludwig WD, Parnes JR, Dörken B. Human Lyb-2 homolog CD72 is a marker for progenitor B-cell leukemias. Am J Hematol. 1992;41(3):151-8.

10. Howard LM, Reen DJ. CD72 ligation regulates defective naive newborn $B$ cell responses. Cell Immunol. 1997;175(2):179-88.

\title{
Clinical and immunological correlations in chronic obstructive pulmonary disease and bronchial asthma
}

\author{
Shuganov E.G. • Raspopina N.A. • Salmasi Zh.M.
}

Shuganov Evgeniy Grigor'evich - MD, PhD, Professor, Internal Diseases Department, Postgraduate Medical School ${ }^{1}$ $\triangle$ 61/2-9 Shchepkina ul., Moscow, 129110, Russian Federation. Tel.: +7 (909) 9883455.

E-mail: shuganov.evgeny@yandex.ru

Raspopina Natal'ya Avtandilovna - MD, $\mathrm{PhD}$, Professor, Internal and Occupational Diseases and Pulmonology Department ${ }^{2}$

Salmasi Zhean Mustafaevich - MD, PhD, Professor, Department of Pathophysiology and Clinical Pathophysiology ${ }^{3}$
Background: To improve differential diagnosis of chronic obstructive pulmonary disease (COPD) and bronchial asthma (BA), identification of new biological markers is needed.

Aim: To differentiate between COPD and BA using modern immunological methods.

Materials and methods: Surface markers of peripheral blood lymphocytes were studied in patients with COPD $(n=37)$ and BA $(n=49)$ exacerbation. Immunological status was also assessed in 24 healthy controls.

Results: In both COPD and BA, typical inflammatory changes of T-lymphocytes, B-lymphocytes and NK-cells counts were found. Lymphocyte surface phenotype changes were significantly different in COPD and BA. In COPD, a significant elevation of blood cytotoxic T-lymphocytes $\left(\mathrm{CD}^{+}\right)$up to $34 \%$ was demonstrated; on the contrary, in BA patients, cytotoxic T-lymphocytes $\left(\mathrm{CD}^{+}\right)$decreased to $21 \%$. CD16+ lymphocytes (NK-cells) were significantly increased (up to 33\%) in COPD patients and corresponded to normal values in BA ( 10\%).

Conclusion: Differences in biological markers in COPD and BA reflect distinct pathogenesis of the diseases and may be used for differential diagnosis.

Key words: chronic obstructive pulmonary disease, bronchial asthma, bronchial and pulmonary immune inflammation, cytotoxic lymphocytes.

'Moscow Regional Research and Clinical Institute (MONIKI); 61/2 Shchepkina ul., Moscow, 129110, Russian Federation ${ }^{2}$ I.M. Sechenov First Moscow State Medical University; 8/2 Trubetskaya ul., Moscow, 119991, Russian Federation ${ }^{3}$ N.I. Pirogov Russian National Research Medical University; 1 Ostrovityanova ul., Moscow, 117997, Russian Federation 